\title{
Meningkatkan Kemampuan Berbahasa Daerah Melalui Cerita Rakyat Digital pada Siswa Sekolah Dasar: Sebuah Studi Pengembangan
}

\author{
Rr. Fadila Kusumaning Ayu ${ }^{1}$, Silvi Puspita Sari ${ }^{2}$, Berliana Yunarti Setiawan ${ }^{3}$, Fifi \\ Khoirul Fitriyah ${ }^{4}$ \\ 1,2,3,4 Universitas Nahdlatul Ulama Surabaya \\ Email: rr.fadila013.sd18@student.unusa.ac.id
}

\begin{tabular}{l|l}
\hline Kata Kunci: & Abstrak \\
\hline $\begin{array}{l}\text { Hikayat } \\
\text { Nusantara, } \\
\text { Aplikasi, }\end{array}$ & $\begin{array}{l}\text { Penelitian ini bertujuan untuk mengembangkan media cerita rakyat digital berupa } \\
\text { aplikasi "Hikanusa" yang digunakan untuk mempertahankan Bahasa Daerah. Jenis } \\
\text { penelitian ini menggunakan Research and Development (R\&D). Uji ahli dilakukan } \\
\text { oleh dua orang yaitu, ahli Sistem Informasi dan ahli pendidikan Bahasa Daerah. }\end{array}$ \\
$\begin{array}{l}\text { Bahasa } \\
\text { Daerah. }\end{array}$ & $\begin{array}{l}\text { Aplikasi "Hikanusa"dapat dijadikan sebagai media pembelajaran bagi siswa sekolah } \\
\text { dasar sehingga siswa mudah belajar bercerita menggunakan Bahasa Daerah. }\end{array}$ \\
& $\begin{array}{l}\text { Harapannya jumlah generasi penutur akan bertambahmencegah dari kepunahan Bahasa } \\
\text { Daerah. Saran untuk penelitian selanjutnya: untuk menguji efektifitas aplikasi } \\
\text { "Hikanusa" menggunakan metode eksperimen. }\end{array}$ \\
\hline Keywords: & $\begin{array}{l}\text { Abstract } \\
\text { Hikayat }\end{array}$ \\
$\begin{array}{l}\text { Nusantara, } \\
\text { Application, }\end{array}$ \\
$\begin{array}{l}\text { Language } \\
\text { Revitalization. }\end{array}$ \\
$\begin{array}{l}\text { Research and Development (R\&D). Expert tests were carried out by two people } \\
\text { namely, Information Systems experts and Regional Language education experts. The } \\
\text { application "Hikanusa" can be used as a learning medium for elementary school } \\
\text { students so that students easily learn to tell stories using the Local Language. It is } \\
\text { hoped that the number of speakers generation will increase to prevent the extinction of } \\
\text { regional languages. Suggestions for further research: to test the effectiveness of the } \\
\text { "Hikanusa" application using the experimental method. }\end{array}$
\end{tabular}

Submission: October 28, 2019. Revised: November 28, 2019. Accepted: December 10, 2019

\section{A. Pendahuluan}

Penggunaan bahasa di seluruh dunia mulai mengalami perseteruan sehingga menyebabkan pergeseran bahasa. Tidak dapat dipungkiri bahwa pergeseran bahasa juga terjadi di Indonesia khususnya Bahasa Daerah. Eksistensi Bahasa Daerah terancam punah ketika penuturnya dibawah ratusan ribu. Menurut Zamzani (2014), bahasa merupakan alat komunikasi untuk mengenal suatu daerah. Dalam hal ini, Kramsch (1998:3) menyatakan bahwa bahasa merupakan alat utama untuk berinteraksi sosial. Dengan adanya bahasa memungkinkan manusia untuk saling memahami, salah satunya melalui penggunaan Bahasa Daerah.

Saat ini Indonesia telah memasuki era revolusi 4.0 sehingga tantangan untuk mempertahankan Bahasa Daerah semakin besar. Hal tersebut di karenakan kondisi masyarakat yang menggunakan kontak bahasa bilingualisme atau multilingualisme yang sering digunakan oleh sekelompok bahasa minoritas (Darwis, 2011). Menurut Lewis (2009), dalam Ethnologue tercatat 7.102 bahasa yang dituturkan di dunia. Indonesia merupakan negara yang memiliki jumlah bahasa terbanyak ke dua setelah New Geria. Indonesia menyumbang sebesar 10,13\% atau sekitar 719 Bahasa Daerah. Sebanyak 707 bahasa (701 bahasa daerah dan 6 bahasa etnik) masih hidup dan masih digunakan oleh penuturnya. Menurut UNESCO (2001), terdapat 640 bahasa di Indonesia, 139 bahasa diantaranya terancam punah, namun 15 bahasa benar-benar dinyatakan punah. 
Selain itu hanya 10 bahasa yang penuturnya di atas satu juta dari 250 juta penduduk Indonesia seperti, Bahasa Jawa (34.300.000 jiwa), Bahasa Sunda (34.000.000 jiwa), Bahasa Madura (13.600.000 jiwa), Bahasa Minangkabau Sumatera Barat (5.530.000 jiwa), Bahasa Musi dari Sumatra Selatan (3.930.000 jiwa), Bahasa Aceh (3.500.000 jiwa), Bahasa Bugis dari Sulawesi Selatan (3.500.000 jiwa), Bahasa Banjar dari Kalimantan Selatan (3.500.000 jiwa), Bahasa Bali (3.330.000 jiwa), Bahasa Betawi (2.700.000 jiwa). Adapun 14 Bahasa Daerah yang dinyatakan punah seperti, bahasa dari Maluku Tengah, yakni bahasa Hoti, Hukumina, Hulung, Serua, Te'un, Palumata, Loun, Moksela, Naka'ela, dan Nila. 12 bahasa lainnya dari Maluku Utara, yakni Ternateno dan Ibu. Adapun 2 bahasa berasal dari Papua, yakni Saponi dan Mapia. hal ini dikarenakan penggunaan Bahasa Daerah cenderung dituturkan oleh masyarakat berusia 50 tahun ke atas.

Pada permasalahan di atas, untuk mengatasi Bahasa Daerah yang terancam punah di Indonesia perlu adanya solusi konkret. Solusi konkret tersebut yaitu, dilakukannya upaya revitalisasi bahasa. Tujuan adanya revitalisasi bahasa yaitu, untuk membantu meningkatkan penggunaan Bahasa Daerah sehingga penutur Bahasa Daerah semakin bertambah dan mencegah kepunahan Bahasa Daerah.

Solusi konkret yang pernah ditetapkan oleh KEMENDIKBUD di Maluku Tengah adalah dilakukannya upaya revitalisasi bahasa dengan menetapkan kebijakan pembelajaran secara umum melalui muatan lokal di sekolah.

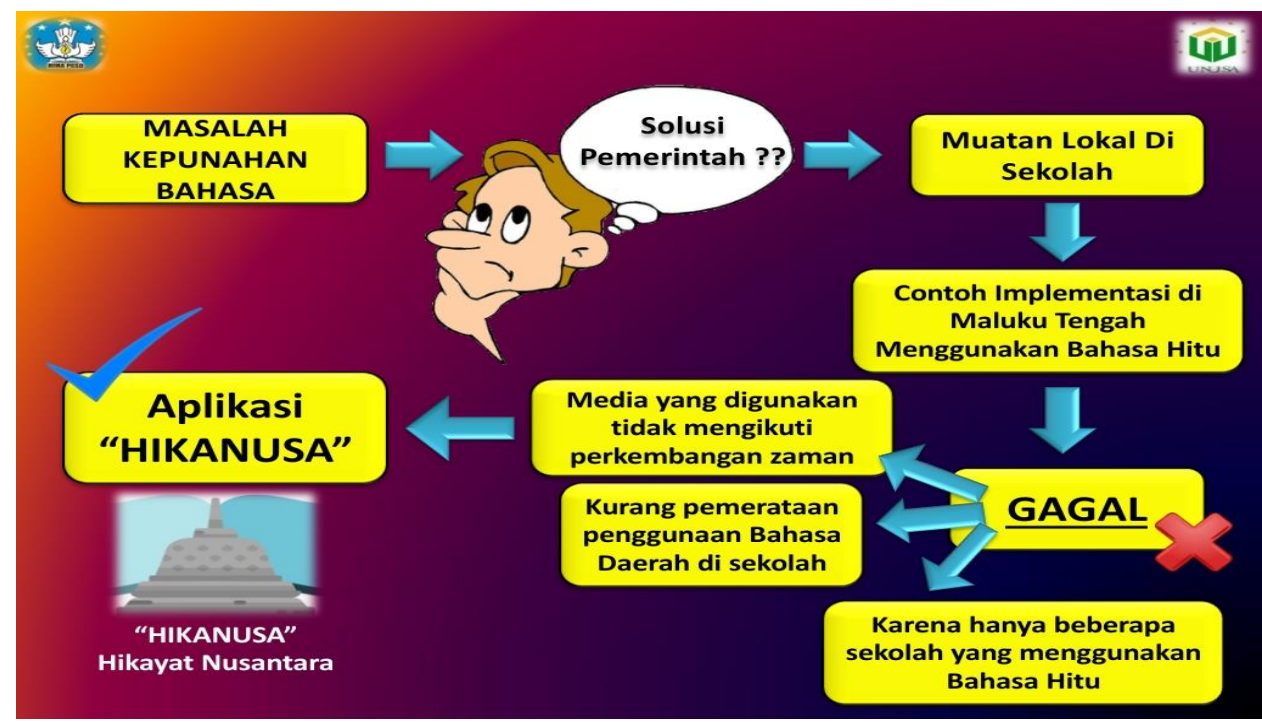

Gambar 1.1 Bagan Permasalahan Bahasa Daerah di Maluku

Menurut Kepala Bidang Perlindungan, Pusat Pengembangan dan Perlindungan Badan Bahasa KEMENDIKBUD memasukkan Bahasa Hitu ke dalam pembelajaran muatan lokal di sekolah, akan tetapi hal tersebut GAGAL dikarenakan hanya beberapa sekolah yang menggunakan Bahasa Hitu. Sehingga kurangnya pemerataan penggunaan bahasa menjadi hambatan dalam penerapan kebijakan yang telah ditetapkan oleh pemerintah. Dengan demikian peneliti merumuskan solusi kongkret dalam upaya revitalisasi Bahasa Daerah melalui tradisi lisan digital.

Pemilihan cerita rakyat Nusantara sebagai upaya revitalisasi bahasa dianggap cocok untuk pengembangan proses belajar Berbahasa Daerah siswa SD, karena alur cerita rakyat ini telah melekat pada sosial kehidupan siswa, sehingga siswa SD dengan mudah memahami alur cerita dan mendapatkan pesan moral yang terkandung dalam cerita rakyat yang dapat menumbuhkan karakter pada diri siswa serta dapat meningkatkan kemampuan Berbahasa 
Daerah. Sebagaiamana Arifin Ahmad (2019) menyampaikan bahwa pendidikan bahasa ini harus disosialisasikan dengan berbagai cara sejak dini, selaras yang ia kerjakan dengan metode 'Permainan Bahasa' telah membuktikan bahwa anak lebih mudah menangkap materi serta ada peningkatan mencapai $13,72 \%$ sesuai indikator yang ia sampaikan.

Hew dan Brush (2007:245), menyebutkan bahwa ruang lingkup pembelajaran secara langsung dapat diterapkan melalui penggunaan teknologi berupa aplikasi untuk siswa. Saat ini siswa SD memasuki generasi alpha sebagai penerus dari generasi sebelumnya yang dikenal dengan generasi Z (Tootell, Freeman, \&Freeman, 2014). Menurut Bennett, Maton, \& Lisa Kervin (2008), kecanggihan penggunaan teknologi informasi dapat menambah pengetahuan dan keterampilan pada generasi alpa sehingga disebut dengan generasi digital native.

Aplikasi "Hikanusa" baru saja diluncurkan pada tanggal 8 Juli 2019 dengan keunggulan, memiliki desain User Interface (UI) ramah pengguna dan mudah dikelola dari sisi admin. "Hikanusa" adalah singkatan dari Hikayat Nusantara sebuah aplikasi E-book berisi cerita rakyat Nusantara. Tujuan adanya aplikasi "Hikanusa" dapat memperkenalkan cerita rakyat Nusantara berbahasa daerah, melalui Siswa SD dan masyarakat luas yang dapat di akses melalui android. Alasan peneliti menggunakan tradisi lisan digital berupa aplikasi "Hikanusa" berbasis android adalah, melihat peluang perkembangan teknologi mobile internet di Indonesia.

Menurut data Asosiasi Penyelenggara Jaringan Internet Indonesia (Fitriani, 2016), mengungkap bahwa lebih dari setengah penduduk Indonesia kini telah terhubung ke internet. Menurut data tersebut, sebanyak 132,7 juta orang, atau lebih dari separuh total populasi Indonesia yang berjumlah 256,2 juta orang telah menggunakan internet (Kompas.com/26/11/2017). Jenis layanan internet yang paling sering dan banyak digunakan adalah internetmobile, pencapaian angka pengguna hingga 92,8 juta atau 69,9 persen. Indonesia menempati peringkat ke-4 dunia dengan durasi rata-rata menggunakan internet selama 8 jam 51 menit setiap harinya. Indonesia berada peringkat ke-7 dunia dengan skor $40 \%$ setelah Nigeria, India, UAE, Maroko, Filiphina dan Kenya (Purnama Sigit, 2018).

Dengan adanya peluang aplikasi "Hikanusa", dapat menjadi salah satu solusi konkret dan sebagai acuan pengenalan Bahasa Daerah melalui cerita rakyat kepada siswa SD dan masyarakat luas, sehingga sangat memungkinkan dapat menambah jumlah generasi penutur di suatu daerah tersebut.

Penelitian ini ingin berfokus padamenghidupkan kembali Bahasa Daerah dan meningkatkan kemampuan penggunaan Bahasa Daerah dengan tradisi lisan digital berupa Aplikasi "Hikanusa" (Hikayat Nusantara) pada siswa Sekolah Dasar.

\section{B. Metode Penelitian}

Penelitian ini menggunakan pendekatan penelitian dan pengembangan. Research and Development (R\&D), merupakan metode penelitian yang digunakan untuk mengembangkan atau memvalidasi produk-produk yang digunakan dalam pendidikan dan pembelajaran (Sugiyono, 2013: 297). Salah satu produknya yaitu aplikasi "Hikanusa".

Tujuan akhir dari R\&D dibidang pendidikan adalah lahirnya produk baru untuk meningkatkan pengetahuan siswa. Dengan demikian melalui hasil R\&D diharapkan proses pendidikan menjadi lebih efektif dan sesuai kebutuhan zaman.

Adapun rancangan pendahuluan dan pengembangan dapat digambarkan dalam bagan 3.1 sebagai berikut. 


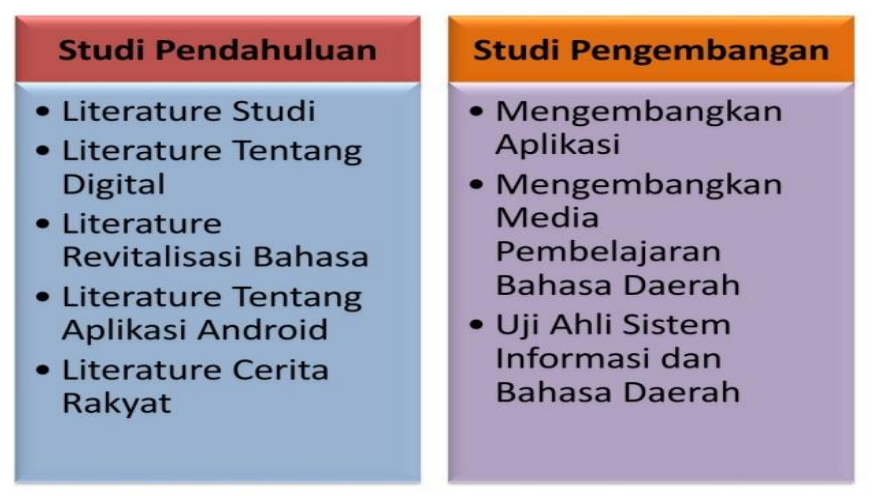

Gambar 2.1 Bagan Pendahuluan dan Pngembangan Metodologi

1. Studi Pendahuluan

Pada tahap ini, dilakukan studi awal untuk mengumpulkan informasi lapangan dalam rangka mencari potensi masalah, serta mengkajinya dengan studi literature berkaitan dengan teori yang akan dikembangkan menjadi model pendidikan Bahasa Daerah melalui cerita rakyat berbasis digital bagi siswa SD dalam upaya pemertahanan Bahasa Daerah.

\section{Pengembangan}

Tahap pengembangan produk merupakan tahap menyusun dan mengembangkan dalam model pendidikan Bahasa Daerah berbasis digital mulai dari pengumpulan cerita rakyat Nusantara, pembuatan aplikasi serta angket yang berisi tanggapan pakar ahli aplikasi oleh Sistem Informasi dan pakar Bahasa Daerah oleh Dosen Fakultas Keguruan dan Ilmu Pendidikan bidang studi Sastra dan Kebahasaan UNUSA.Pengembangan pendidikan Bahasa Daerah berbasis digital berupa aplikasi "Hikanusa" (Hikayat Nusantara) yang terdiri dari konten cerita rakyat Nusantara berbahasa daerah.Aplikasi tersebut akan divalidasi dan direvisi sehingga diperoleh model dan instrument yang valid, reliabel, praktis, dan efektif untuk dilaksanakan.

\section{Hasil Dan Pembahasan}

Digitalisasi bahasa merupakan proses pemakaian bahasa dengan sistem digitalyang di kembangkan melalui tradisi lisan digital. Tradisi lisan digital merupakan sebuah tradisi lisan yang digunakan masyarakat untuk berkomunikasi dan dikombinasi dengan sistem digital. Salah satu contoh tradisi lisan adalah cerita rakyat. Adanya inovasi tradisi lisan digital sebagai salah satu media pembelajaran dalam upaya pembaruan serta mewujudkan peningkatan kualitas pendidikan. Seiring pesatnya perkembangan zaman, eksistensi Bahasa Daerah semakin terancam. Maka dari itu, perlu adanyapeningkatan pembelajaran Bahasa Daerah supaya kebudayaan bahasa tidak hilang.

Adapun hasil pemetakan kepunahan bahasa lokal di Indonesia diantaranya, lebih dari 50 bahasa daerah di Kalimantan, satu di antaranya terancam punah. Di Sumatera, dari 13 bahasa daerah yang ada, dua di antaranya terancam punah dan satu lainnya sudah punah. Namun, di Jawa tidak ada bahasa daerah yang terancam punah. Adapun di Sulawesi dari 110 bahasa yang ada, 36 bahasa terancam punah dan 1 sudah punah, di Maluku dari 80 bahasa yang ada 22 terancam punah dan 11 sudah punah, di daerah Timor, Flores, Bima dan Sumba dari 50 bahasa yang ada, 8 bahasa terancam punah. Di daerah Papua dan Halmahera dari 271 bahasa, 56 bahasa terancam punah. Pada kasus tanah Papua, 9 bahasa dinyatakan telah punah, 32 bahasa segera punah, dan 208 bahasa terancam punah. Kenyataan tersebut akan menjadikan kita prihatin apabila proses kepunahan bahasa lokal dikaitkan dengan ancaman kepunahan budaya lokal di setiap daerah. 
Cara konkrit pemertahanan Bahasa Daerah yaitu dengan dilakukannya revitalisasi bahasa yang mampu memfasilitasi pelestarian Bahasa Daerah khususnya di Sekolah Dasar. Revitaisasi bahasa adalah suatu usaha untuk meningkatkan daya hidup suatu bahasa. Revitalisasi bahasa bertujuan untuk meningkatkan penggunaan bahasa, sehingga penutur bahasa daerah semakin bertambah dan mencegah kepunahan Bahasa Daerah di suatu daerah. Sekolah Dasar merupakan jenjang dasar pendidikanformal di Indonesia. Pada saat di jenjang Sekolah Dasar inilah pondasi awal dimana anak mulai belajar dan mengenal lingkungan sekitarnya. Pada usia ini anak masih mudah terpengaruh, sehingga adanya peluang bagi guru untuk menanamkan modal yang baik pada diri anak khususnya pemberian bekal pengetahuan Bahasa Daerah yang dimiliki daerahnya.

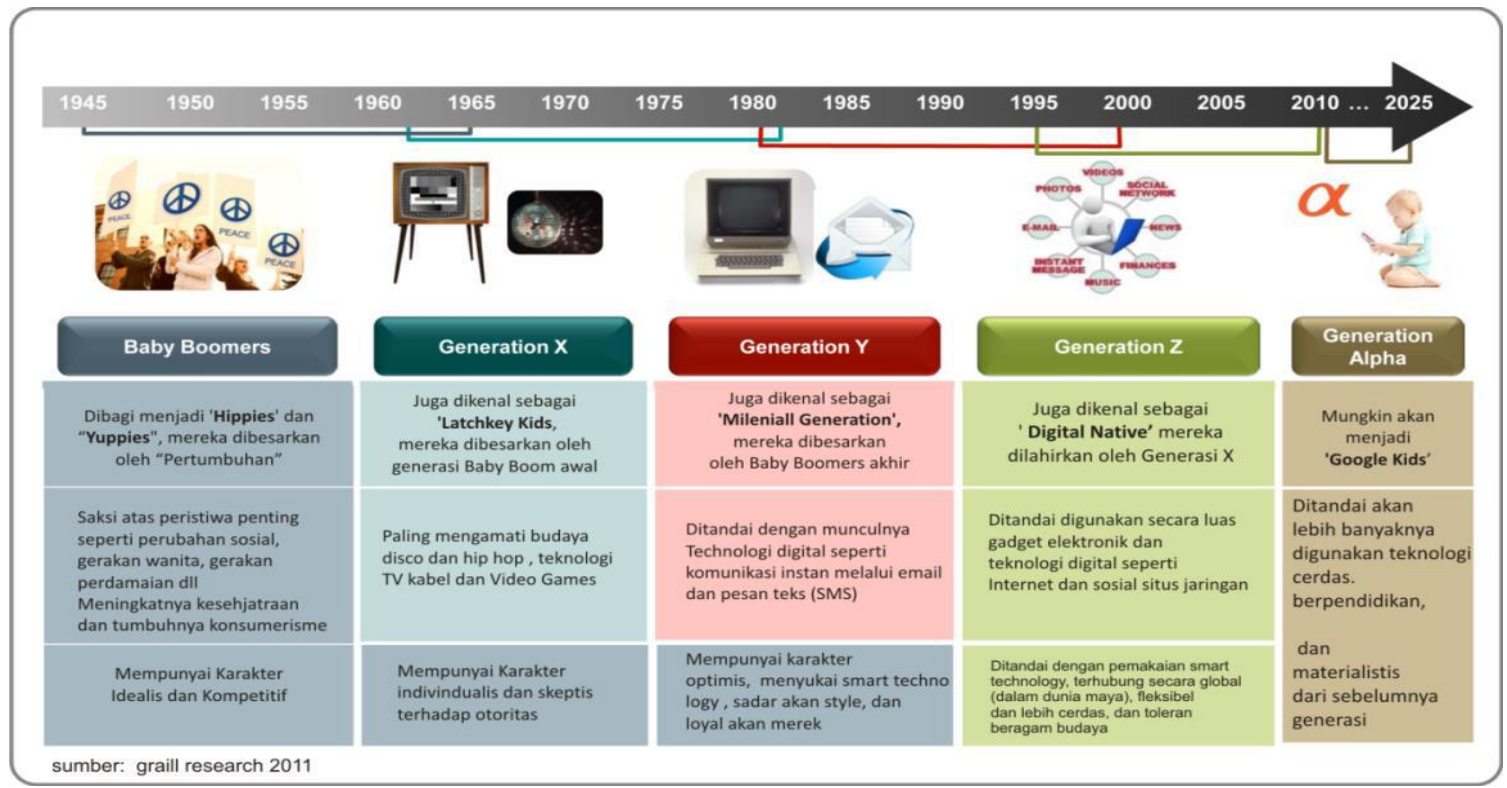

Gambar 3.1 Termonilogi Generasi Teknologi Berdasar Tahun Kelahiran

Berdasarkan gambar diatas, menunjukkan perkembangan generasi disetiap tahunnya, serta percepatan perkembangan teknologi informasi yang bisa berpengaruh pada upaya revitalisasi tradisi lisan cerita rakyat dan cara menjadikan teknologi sebagai kesempatan untuk melakukan revitalisasi, karena faktanya tradisi itu bersifat dinamik dan menyesuaikandengan zaman terutama dengan perkembangan budaya berupa alat teknologi.

Dengan adanya revitalisasi bahasa melalui tradisi lisan digital berupa aplikasi "Hikanusa", mampu memberikan kontribusi dalam upaya pelestarian bahasa daerah melalui siswa SD. "Hikanusa" (Hikayat Nusantara) adalah sebuah aplikasi berbasis android dan berfungsi untuk memudahkan anak bangsa mengenal dan mempelajari bahasa daerahnya melalui cerita rakyat Nusantara. Aplikasi "Hikanusa" ini tidak hanya terfokuskan untuk siswa Sekolah Dasar, namun juga bisa digunakan oleh siswa yang berada di jenjang setelahnya serta orang orang dewasa yang ingin belajar akan Bahasa Daerah disuatu wilayah tertentu. Karena untuk mengetahui kekayaan lokal suatu daerah harus memiliki kemampuan pemahaman bahasa yang digunakan pada daerah tersebut.

"Hikanusa" merupakan, sebuah aplikasi cerita rakyat pengembangan dari tradisi lisan digital yang di bangun untuk mendokumentasikan beberapa cerita rakyat dari seluruh Nusantara. "Hikanusa" dapat diakses melalui Google Play Store. 


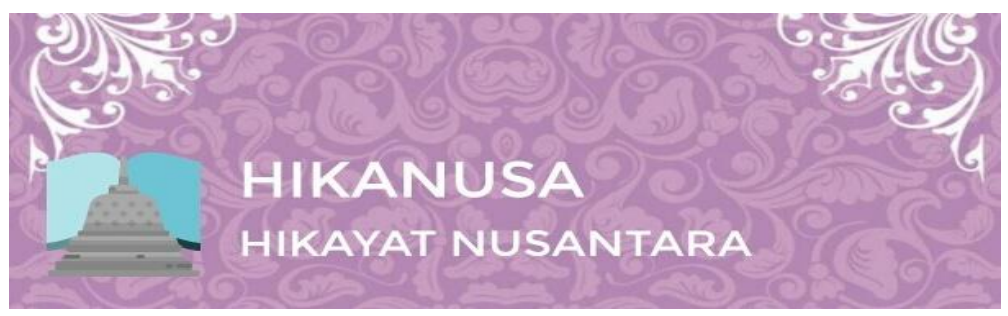

Gambar 3.2 Aplikasi "Hikanusa"

Aplikasi "Hikanusa" baru saja diluncurkan pada tanggal 8 Juli 2019 dengan keunggulan, memiliki desain User Interface (UI) ramah pengguna dan mudah dikelola dari sisi admin. Aplikasi ini di optimalkan secara khusus supaya mudah di konfigurasikan. Fungsi aplikasi "Hikanusa" adalah sebagai E-book cerita Nusantara dari Mahasiswa Indonesia untuk Indonesia. Tujuan adanya aplikasi "Hikanusa" dapat memperkenalkan cerita rakyat Nusantara berbahasa daerah, melalui Siswa SD dan masyarakat luas yang dapat di akses melalui android.

Adapun fitur-fitur yang terdapat pada aplikasi "Hikanusa" diantaranya adalah:

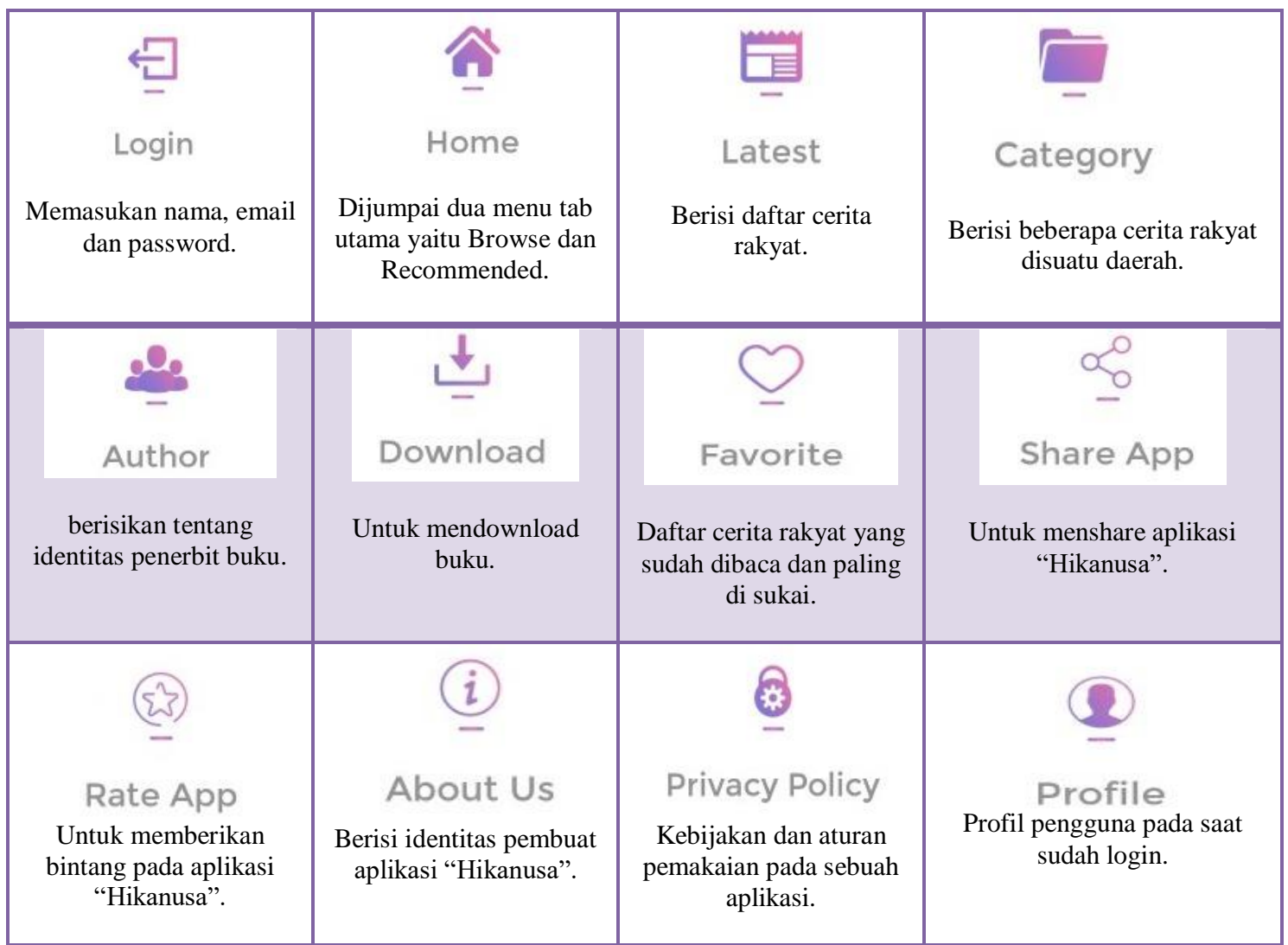

Gambar 3.3 Fitur Fitur pada Aplikasi Hikanusa

Selain dapat dijadikan media pembelajaran moral, aplikasi "Hikanusa" ini, bisa digunakan sebagai media pembelajaran Bahasa Daerah dan memperkenalkan Bahasa Daerah sekaligus cerita rakyat yang berada di daerahnya, sehingga siswa dengan mudah belajar bercerita menggunakan bahasa daerah tersebut. Dengan demikian, secara otomatis jumlah generasi penutur Bahasa Daerah yang berada di suatu daerah tertentu semakin bertambah. 


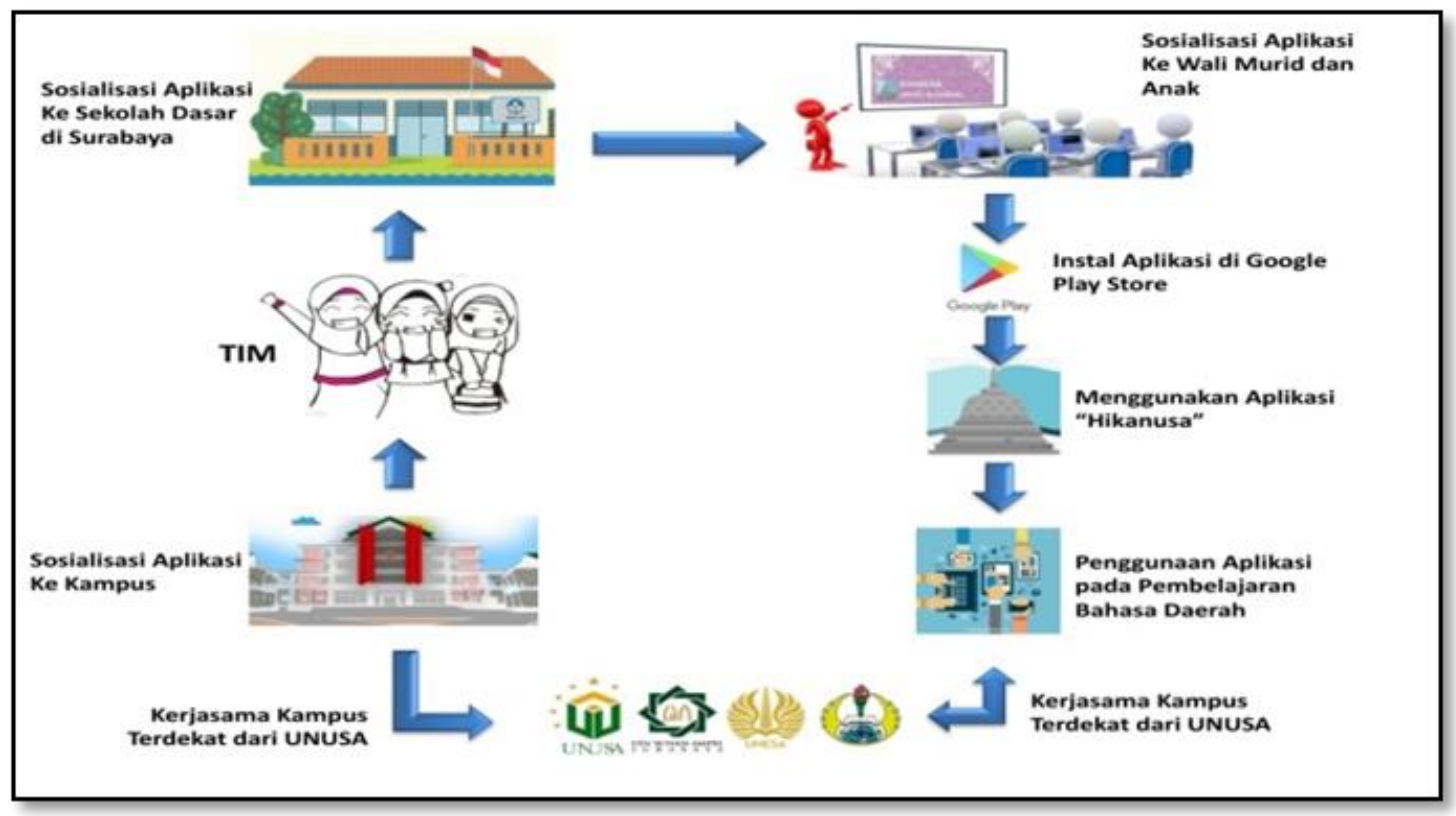

Gambar 3.4 Skema Sosialisasi Aplikasi

TIM dari aplikasi "Hikanusa" melakukan sosialisasi ke sekolah dasar yang ada di Surabaya dengan tujuan memperkenalkan aplikasi "Hikanusa" yang dapat digunakan untuk memperkenalkan cerita rakyat Berbahasa Daerah. Kemudian TIM, mensosialisasikan kepada wali murid dan siswa untuk memperkenalkan aplikasi"Hikanusa" sehingga dapat di instalmelalui "Google Play Store". TIMjuga melakukan sosialisasi aplikasi ke kampus di sekitar Surabaya diantaranya, UNUSA, UINSA, UNESA, dan UNIPA dengan tujuan supaya mahasiswa/i khususnya Fakultas Keguruan dan Ilmu Pendidikan Prodi PGSD dapat menggunakan aplikasi "Hikanusa" sebagai acuan untuk memperkenalkan Bahasa Daerah dan Cerita Rakyat kepada siswa SD.

\section{Kesimpulan}

Perkembangan teknologi tidak dapat dihindari terutama di era revolusi 4.0. Siswa SD saat ini sangat terampil dalam penggunaan teknologi yang di design khusus dengan sistem aplikasi Bahasa Inggris sehingga Bahasa Inggris menjadi kebutuhan utama agar dapat bersaing di era global. Dengan demikian eksistensi Bahasa Daerah akan terancam karena berkurangnya generasi penutur di suatu daerah tersebut. Maka perlu dilakukannya upaya revitalisasi bahasa melalui inovasi tradisi lisan digital berupa aplikasi "Hikanusa" yang mampu memberikan kontribusi dalam upaya pelestarian Bahasa Daerah.

Aplikasi "Hikanusa" baru saja diluncurkan pada tanggal 8 Juli 2019 dengan keunggulan, memiliki desain User Interface (UI) ramah pengguna dan mudah dikelola dari sisi admin. Penelitian ini bertujuan untuk mengembangkan media cerita rakyat digital berupa aplikasi "Hikanusa" yang digunakan untuk mempertahankan Bahasa Daerah. Cerita Rakyat ini bagus dan cocok untuk siswa SD serta, dapat dijadikan media pembelajaran untuk menanamkan nilai moral yang baik, media pembelajaran Bahasa Daerah dan memperkenalkan Bahasa Daerah sekaligus cerita rakyat yang berada di daerahnya, sehingga siswa dengan mudah belajar bercerita menggunakan bahasa daerah tersebut. Dengan demikian jumah generasi penutur akan bertambah. 
Diharapkan adanya penelitian selanjutnya untuk menguji efektif "Hikanusa" secara lebih luas. Para guru diharapkan menggunakan aplikasi "Hikanusa" dalam pembelajaran di kelas. Pemerintah daerah diharapkan dapat memfasilitasi siswa-siswi di sekolah khususnya di pelosok agar dapat aksesibilitas internet secara maksimal.

\section{Daftar Pustaka}

Arifin, A. (2019). Penggunaan Permainan Bahasa untuk Meningkatkan Aktifitas Siswa kelas IV A SD Negeri 01 Metro Pusat. Child Education Journal, Vol 1(1), 26. https://doi.org/ 10.33086/cej.v1i1.1052

Bennett, S., Maton, K., \& Lisa Kervin. 2008. The "digital natives" debate: Acritical review of the evidence. British Journal of Educational Technology, 39(5), 775-786. https://doi.org/ 10.1111/j.1467-8535.2007.00742.x.

Darwis, M. (2011). Nasib Bahasa Daerah di Nusantara. Jakarta: Researchgate.

Fitriani, R., \& Tajuddin, M. (2016). Desain Sistem Informasi Sekolah Berbasis Android. Matrik, 16 (1), 12-21.

Hew, K. F. dan Brush, Thomas. (2007). Integrating technology into K-12 teaching andlearning: current knowledge gaps and recommendations for future research. Education Tech Research Dev.

Kemendikbud. (2018). Pengutamaan Penggunaan Bahasa Negara. Jakarta: Kemendikbud.

Kompas.com, "Tahun 2016 Pengguna Internet di Indonesia Capai 132 Juta, ”Accessed: 26 November 2017.

Kramsch, Claire. (1998). Language and Culture. Oxford: Oxford Unvesity Press.

Lewis, M. Paul (ed). (2009). Ethnologue Languages of World. Sixteen edition. Dallas, Tex: SIL Internasional.

Sugiyono. (2013). Metode Penelitian Kuantitatif, Kualitatif, dan R \& D. Bandung: Alfabeta.

Tootell, H., Freeman, M., \& Freeman, A. (2014). Generation alpha at theintersection of technology, play and motivation. In Proceedings of the Annual Hawaii International Conference on System Sciences (hal. 82-90). IEEE.https://doi.org/10.1109/HICSS. 2014.19.

UNESCO. (2001). Information and Communication Technology in Education: Acurriculum for school and programme of theacher development. Eds, J. Anderson and T Van Weert. UNESCO, Paris.

Zamzani. 2014. Eksistensi Bahasa Dalam Pendidikan Berbasis KeragamanBudaya. Jurnal Dialektika, Vol. 1 (2), 225-244. 